TUBERCULOSIS

\title{
Gender differentials of pulmonary tuberculosis transmission and reactivation in an endemic area
}

\author{
M-E Jiménez-Corona, L García-García, K DeRiemer, L Ferreyra-Reyes, M Bobadilla- \\ del-Valle, B Cano-Arellano, S Canizales-Quintero, A Martínez-Gamboa, P M Small, \\ J Sifuentes-Osornio, A Ponce-de-León
}

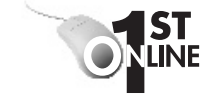

Thorax 2006;61:348-353. doi: 10.1136/thx.2005.049452

See end of article for authors' affiliations

.....................

Correspondence to: Dr L García-García, Director of the Tuberculosis Unit, Instituto Nacional de Salud Pública, $7^{a}$ Cerrada de Fray Pedro de Gante No 50; Col. Sección XVI, Deleg Tlalpan, México, DF México; C.P. 14000; garcigar@correo.insp.mx

Received 18 July 2005

Accepted 23 January 2006

Published Online First

31 January 2006
Background: In most low income countries there are twice as many cases of tuberculosis (TB) reported among men than among women, a difference commonly attributed to biological and epidemiological characteristics as well as socioeconomic and cultural barriers in access to health care. The World Health Organization has encouraged gender specific comparisons in TB rates to determine whether women with TB are less likely than men with TB to be diagnosed, reported, and treated. A study was undertaken to identify gender based differences in patients with pulmonary TB and to use this information to improve TB control efforts.

Methods: Individuals with a cough for more than 2 weeks in southern Mexico were screened from March 1995 to April 2003. Clinical and mycobacteriological information (isolation, identification, drug susceptibility testing and IS6110 based genotyping, and spoligotyping) was collected from those with bacteriologically confirmed pulmonary TB. Patients were treated in accordance with official norms and followed to ascertain treatment outcome, retreatment, and vital status.

Results: 623 patients with pulmonary TB were enrolled. The male:female incidence rate ratio for overall, reactivated, and recently transmitted disease was 1.58 (95\% $\mathrm{Cl} 1.34$ to 1.86$), 1.64$ (95\% Cl 1.36 to 1.98), and $1.41(95 \% \mathrm{Cl} 1.01$ to 1.96$)$, respectively. Men were more likely than women to default from treatment (adjusted OR 3.30, 95\% Cl 1.46 to 7.43), to be retreated (hazard ratio (HR) 3.15, 95\% Cl 1.38 to 7.22 ), and to die from TB (HR 2.23, 95\% Cl 1.25 to 3.99).

Conclusions: Higher rates of transmitted and reactivated disease and poorer treatment outcomes among men are indicators of gender differentials in the diagnosis and treatment of pulmonary TB, and suggest specific strategies in endemic settings.
$\mathrm{T}$ uberculosis (TB) is the leading cause of death from an infectious disease in women worldwide. ${ }^{1}$ In most low income countries twice as many cases of TB are reported among men than among women, ${ }^{2}$ a difference commonly attributed to biological and epidemiological characteristics ${ }^{34}$ as well as socioeconomic and cultural barriers in access to health care. ${ }^{5}$ The World Health Organization (WHO) has encouraged gender specific comparisons in TB rates to determine whether women with $\mathrm{TB}$ are less likely than men with TB to be diagnosed, reported, and treated. ${ }^{5}$

We have been conducting a population based prospective study of pulmonary TB in southern Mexico since 1995. According to the 2000 census, women have less literacy, fewer years of formal education, and higher rates of unemployment in the study area. These indicators are comparable to the state and nationwide rates. ${ }^{6}$ Individuals who report a cough (>2 weeks) are detected and screened and, if they are diagnosed with TB, they are referred to an appropriate healthcare provider for treatment. In this study we sought to determine whether there were gender differences in the incidence rates of bacteriologically proven pulmonary $\mathrm{TB}$, the percentage of pulmonary $\mathrm{TB}$ cases due to recent transmission versus reactivation of latent infection, and the treatment outcomes of patients with bacteriologically proven pulmonary TB.

\section{METHODS}

Study population and enrolment

The study site and enrolment procedures have been described previously. ${ }^{7}$ Briefly, the study area includes 12 municipalities in the Orizaba Health Jurisdiction in Veracruz State, Mexico. The study area is $618.11 \mathrm{~km}^{2}$ and has 369235 inhabitants, $14.9 \%$ of them in rural communities. ${ }^{8}$ The incidence rate of $\mathrm{TB}$ in the state of Veracruz during 2000 (28.0 cases per 100000 population) was higher than the incidence rate nationwide (15.9 cases per 100000 population). ${ }^{9}$ We performed passive case finding supported by community based health workers and screened persons who reported coughing for more than 15 days. Collaboration was established with local health and political authorities for recruitment of participants. The register of TB patients was reviewed periodically to identify patients with pulmonary $\mathrm{TB}$ who might have been missed by recruiters.

Between March 1995 and April 2003, patients with acid fast bacilli (AFB) or Mycobacterium tuberculosis in sputum samples were evaluated using a standardised questionnaire, physical examination, chest radiography, and HIV testing to determine their epidemiological, clinical, and mycobacteriological characteristics. Treatment was provided using the official norms of Mexico's national TB control program. ${ }^{10}$ Annual follow up was performed to ascertain treatment outcome and vital status, as previously described. ${ }^{11}$ Deaths were attributed to TB based on two of the following: death certificate with TB as the main cause of death; interview with a close caregiver who identified TB as a probable cause of death; or bacteriologically confirmed $\mathrm{TB}$ at the time of death. $^{12}$

Abbreviations: AFB, acid fast bacilli; DOTS, directly observed therapy; $T B$, tuberculosis 
Written informed consent was obtained from each individual before enrolment. The study was approved by the institutional review boards of the Instituto Nacional de Salud Pública (INSP), the Instituto Nacional de Ciencias Médicas y de la Nutrición "Salvador Zubirán" (INCMNSZ), and Stanford University.

\section{Mycobacteriology and genotyping}

Ziehl Neelsen staining, cultures for mycobacteria, species identification, and susceptibility testing were performed following standardised procedures. ${ }^{11}{ }^{13}$ Genotypic analysis of $M$ tuberculosis isolates was carried out using a standard insertion sequence IS6110 restriction fragment length polymorphism (RFLP) technique with computer assisted analysis of the patterns (Bioimage AQ-1 Analyzer and Molecular Fingerprinting Analyzer, Version 2.0). Isolates with identical IS6110 genotype patterns with fewer than six hybridising bands were also analysed using spoligotyping as previously described. ${ }^{11}{ }^{14}$ Because we were interested in assessing recent or ongoing transmission of $M$ tuberculosis that rapidly progressed to disease, we established a 1 year period for defining clustering. Cases were considered "clustered" if two or more isolates from different patients were identified within 12 months of each other and had six or more IS6110 bands in an identical pattern, or fewer than six bands with identical IS6110 RFLP patterns and a spoligotype with the same spacer oligonucleotides. Pulmonary TB cases with a unique genotype pattern and the first case diagnosed in each cluster probably arose from the reactivation of a latent TB infection.

\section{Statistical analysis}

To determine if women were less likely to undergo screening than men, we compared the proportion of women among screened individuals with the proportion of women in the general population as measured by the 2000 census, ${ }^{15}$ and the proportion of women providing three sputum samples with the proportion of men.

We estimated the incidence rate of bacteriologically proven pulmonary $\mathrm{TB}$ by gender and by clustered versus unique genotype patterns. The incidence rate of pulmonary TB cases was calculated using the census data for the population $\geqslant 15$ years of age as the denominator. ${ }^{15}$ An annual population estimate was extrapolated for non-census years assuming a steady annual growth rate in the geographical study area.

Bivariate and multivariate analyses were used to test for gender based differences in the patients sociodemographic, behavioral, and clinical characteristics. The bacteriological characteristics of the isolates of $M$ tuberculosis (such as drug susceptibility test results and genotype patterns) from men and women were compared. To evaluate access to health care, we assessed the severity of symptoms and disease at diagnosis, the distance to health service centres, the time for which the patient was symptomatic before diagnosis, the time elapsed between diagnosis and starting antituberculosis treatment, and the time elapsed between the onset of symptoms and the start of antituberculosis treatment. Associations between gender and treatment outcome were investigated by multivariate unconditional logistic regression. Kaplan-Meier curves were used to assess survivorship by gender and a log rank test was used to detect significant differences. ${ }^{16}$ We also constructed Cox proportional hazards models to determine the association of gender with time to retreatment and death. Variables were entered into the models according to their statistical significance in the bivariate analysis $(p \leqslant 0.2)$ and their biological relevance, and were retained based on the $\chi^{2}$ test of the log likelihood ratios. Stata version 7.0 statistical software (Stata Corp, College Station, Texas, USA) was used for data analysis.

\section{RESULTS}

During the 8 year study period we screened 8195 individuals with a cough lasting $>2$ weeks, 4569 (55.7\%) of whom were women. This proportion was larger than the proportion of women in the general population as measured by the 2000 census $(\mathrm{n}=176120,47.7 \%, \mathrm{p}<0.0001)$. Age distribution of the group who presented with cough was similar to the general population. $86 \%$ of all those with a cough provided three sputum samples; the proportion of women who provided three samples ( $\mathrm{n}=3948,86.4 \%$ ) was slightly higher than the proportion of men $(\mathrm{n}=3067,84.6 \%, \mathrm{p}=0.03)$. Of all the individuals who were screened, 829 (10.1\%) had AFB or $M$ tuberculosis in at least one sputum sample and were diagnosed with pulmonary TB.

Mycobacteriological culture and genotyping results were obtained for 623 of the 829 TB patients (75.1\%). Patients with an $M$ tuberculosis genotype available were more likely than those who were unable to perform a genotype study to have $>10$ bacilli per oil immersion field in the sputum smear (257/ $623(41.3 \%) v 54 / 206(26.2 \%), p=0.001)$ and severe clinical symptoms such as fever (416/623 (66.8\%) v 115/206 (55.8\%), $\mathrm{p}=0.004)$ or initial weight loss $(468 / 622(75.2 \%) v 139 / 206$ $(67.5 \%), p<0.05)$.

\section{Incidence rates and incidence rate ratio by gender}

Of the 623 pulmonary TB patients, 256 (41.1\%) were women. Overall, the incidence rate of pulmonary TB was $58 \%$ higher in men (31.79 cases per 100000 person-years) than in women ( 20.13 cases per 100000 person-years, $p<0.001$ ). The incidence rates of clustered pulmonary TB cases in men and women, representing ongoing transmission ( $7.54 v 5.35$ cases per 100000 person-years) and reactivated cases of TB (24.25 $v 14.78$ cases per 100000 person-years), were also higher in men than in women $(\mathrm{p}<0.05$ and $\mathrm{p}<0.001$, respectively).

\begin{tabular}{|c|c|c|c|c|}
\hline Variables & Rate $^{*}$ in men & Rate $^{*}$ in women & $\begin{array}{l}\text { Incidence rate ratio } \\
\text { men:women }(95 \% \mathrm{Cl})\end{array}$ & $p$ value \\
\hline \multicolumn{5}{|l|}{ Incidence rates } \\
\hline Clustered cases $†$ & $7.54(n=87)$ & $5.35(n=68)$ & 1.41 (1.01 to 1.96$)$ & 0.03 \\
\hline Reactivated cases & $24.25(n=280)$ & $14.78(n=188)$ & 1.64 (1.36 to 1.98$)$ & $<0.001$ \\
\hline Total cases & $31.79(n=367)$ & $20.13(n=256)$ & 1.58 (1.34 to 1.86$)$ & $<0.001$ \\
\hline \multicolumn{5}{|l|}{ Mortality rates } \\
\hline Due to $T B$ & $3.20(n=37)$ & $1.10(n=15)$ & 2.91 (1.60 to 5.30 ) & 0.0003 \\
\hline All cause mortality & $7.61(n=88)$ & $2.20(n=30)$ & 3.46 (2.28 to 5.23$)$ & $<0.0001$ \\
\hline
\end{tabular}


Table 2 Characteristics of patients with pulmonary TB by gender, Orizaba, Veracruz, 1995-2003

\begin{tabular}{|c|c|c|c|c|}
\hline Characteristics & Total & $\begin{array}{l}\text { Men } \\
(n=367) \S\end{array}$ & $\begin{array}{l}\text { Women } \\
(n=256) \S\end{array}$ & $p$ value \\
\hline Mean (SD) age (years) & $44.3(17.8)$ & $45.19(17.3)$ & $43.12(18.5)$ & $0.15^{*}$ \\
\hline Any formal education, $\mathrm{n}(\%)$ & $505 / 620(81.45)$ & $313 / 365(85.75)$ & $192 / 255$ (75.29) & 0.001 \\
\hline $\begin{array}{l}\text { Potable water available within the } \\
\text { household, } \mathrm{n}(\%)\end{array}$ & $246 / 606(40.59)$ & $157 / 357(43.98)$ & $89 / 249(35.74)$ & 0.04 \\
\hline $\begin{array}{l}\text { Median (IQR) distance to nearest } \\
\text { health centre (metres) }\end{array}$ & $691.81(436.94-1012.05)$ & $686.93(437.35-980.23)$ & 705.47 (430.94-1211.67) & $0.24 \dagger$ \\
\hline Used alcohol, $n(\%)$ & $285(45.97)$ & $255 / 365(69.86)$ & $30 / 255(11.76)$ & $<0.001$ \\
\hline Used tobacco, $\mathrm{n}(\%)$ & $169 / 620(27.26)$ & $150 / 365(41.10)$ & $19 / 255(7.45)$ & $<0.001$ \\
\hline Used illegal drug, $\mathrm{n}(\%)$ & $43 / 620(6.94)$ & $42 / 365(11.51)$ & $1 / 255(0.39)$ & $<0.001$ \\
\hline Homelessness or residence in shelters, $\mathrm{n}(\%)$ & $23 / 619(3.72)$ & $22 / 364(6.04)$ & $1 / 255(0.39)$ & $<0.001$ \\
\hline Previous imprisonment, $\mathrm{n}(\%)$ & $168 / 619(27.14)$ & $161 / 365(44.11)$ & $7 / 254(2.76)$ & $<0.001$ \\
\hline HIV infection, $n(\%)$ & $15 / 601(2.50)$ & $10 / 352(2.84)$ & $5 / 249(2.01)$ & 0.52 \\
\hline Weight loss, $\mathrm{n}(\%)$ & $522 / 611(85.43)$ & $319 / 361$ (88.37) & $203 / 250(81.20)$ & 0.01 \\
\hline Haemoptysis, n (\%) & $205 / 619(33.12)$ & $140 / 364(38.46)$ & $65 / 255(25.49)$ & 0.001 \\
\hline Cavities on chest radiograph, $\mathrm{n}(\%)$ & $174 / 521(33.40)$ & $98 / 298$ (32.89) & $76 / 223(34.08)$ & 0.77 \\
\hline Infiltrates on chest radiograph, $\mathrm{n}(\%)$ & $358 / 531(67.42)$ & $230 / 305(75.41)$ & $128 / 226(56.64)$ & $<0.001$ \\
\hline Clustered genotype pattern $\ddagger$ & $155 / 623(24.88)$ & $87 / 367(23.71)$ & $68 / 256(26.56)$ & 0.42 \\
\hline $\begin{array}{l}\text { Median (IQR) interval between initiation } \\
\text { of symptoms and diagnosis (months) }\end{array}$ & $2.87(1.70-5.47)$ & $2.90(1.70-5.57)$ & $2.78(1.63-5.0)$ & $0.46 \dagger$ \\
\hline $\begin{array}{l}\text { Median (IQR) interval between initiation } \\
\text { of symptoms and treatment (months) }\end{array}$ & $3.37(2.07-5.97)$ & $3.50(2.10-6.20)$ & $3.25(2.02-5.40)$ & $0.18 \dagger$ \\
\hline $\begin{array}{l}\text { Median (IQR) interval between diagnosis } \\
\text { and initiation of treatment (months) }\end{array}$ & $0.20(0.07-0.43)$ & $0.20(0.07-0.047)$ & $0.02(0.07-0.37)$ & $0.22 \dagger$ \\
\hline $\begin{array}{l}M \text { tuberculosis resistant to isoniazid } \\
\text { and rifampin, } \mathrm{n}(\%)\end{array}$ & $36 / 618(5.83)$ & $19 / 366$ (5.19) & $17 / 252(6.75)$ & 0.42 \\
\hline $\begin{array}{l}\text { Initiation of treatment }<10 \text { days } \\
\text { after diagnosis, } \mathrm{n}(\%)\end{array}$ & $408 / 576(70.83)$ & $242 / 346(69.94)$ & $166 / 230(72.17)$ & 0.56 \\
\hline Directly supervised treatment, $\mathrm{n}(\%)$ & $551 / 562(98.04)$ & $333 / 339$ (98.23) & $218 / 223(97.76)$ & 0.69 \\
\hline \multicolumn{5}{|l|}{ Treatment outcome, $\mathrm{n}(\%)$} \\
\hline Cure & $471 / 568$ (82.92) & $273 / 343$ (79.59) & $198 / 225(88.0)$ & 0.009 \\
\hline Default & $52 / 568(9.15)$ & $41 / 343$ (11.95) & $11 / 225(4.89)$ & 0.002 \\
\hline Retreatment during follow up & $47 / 606(7.10)$ & $36 / 355(9.30)$ & $10 / 251(3.98)$ & 0.01 \\
\hline Mean (SD) follow up (months) & $40.81(32.43)$ & $48.33(33.43)$ & $49.48(30.98)$ & $0.66^{*}$ \\
\hline Death from TB, n (\%) & $52 / 623(8.35)$ & $37 / 367(10.08)$ & $15 / 256(5.86)$ & 0.06 \\
\hline
\end{tabular}

Mortality due to TB was higher in men (3.2 per 100000 person-years) than in women (1.1 per 100000 person-years, $\mathrm{p}=0.0003$; table 1 ).

\section{Characteristics of clusters by gender}

Of the 623 isolates of $M$ tuberculosis with a genotype result, $155(24.8 \%)$ were in clusters and $468(75.1 \%)$ had a unique genotype. There were 43 different clusters, each with 2-19 isolates; $29(67 \%)$ of index cases were male. Clusters with a female index case were not significantly larger (mean 3.8, median 2.5, range 2-9) than clusters initiated by men (mean 3.4 , median 2.0 , range $2-19, \mathrm{p}=0.5)$. Similarly, there was no significant difference in the number of secondary cases by gender.

Table 3 Results of multivariate analysis of risk factors for default, retreatment, and death from TB among bacteriologically confirmed pulmonary TB patients, Orizaba Veracruz, 1995-2003

\begin{tabular}{|c|c|c|c|c|c|c|}
\hline \multirow[b]{2}{*}{ Characteristic } & \multicolumn{2}{|l|}{ Default } & \multicolumn{2}{|l|}{ Retreatment } & \multicolumn{2}{|l|}{ Death from TB } \\
\hline & $\mathrm{OR}^{*}(95 \% \mathrm{CI})$ & p value & $\mathrm{HR} \dagger(95 \% \mathrm{Cl})$ & p value & $\mathrm{HR} \dagger(95 \% \mathrm{CI})$ & $p$ value \\
\hline Men & 3.30 (1.46 to 7.43$)$ & 0.004 & 3.15 (1.38 to 7.22$)$ & 0.007 & 2.23 (1.25 to 3.99 ) & 0.007 \\
\hline Age (years) & - & - & - & - & 1.04 (1.02 to 1.05 ) & $<0.001$ \\
\hline No formal education & 3.85 (1.85 to 8.33 ) & $<0.001$ & - & - & - & - \\
\hline No social security & 4.54 (1.64 to 12.5$)$ & 0.003 & - & - & - & - \\
\hline Body mass index & - & - & - & - & 2.28 (1.38 to 3.79$)$ & 0.001 \\
\hline Weight loss & - & - & - & - & 2.40 (1.02 to 5.63$)$ & 0.04 \\
\hline Diabetes & - & - & 1.83 (0.94 to 3.54$)$ & 0.073 & - & - \\
\hline HIV infection & - & - & - & - & 24.30 (9.0 to 65.6$)$ & $<0.001$ \\
\hline MDR TB & - & - & 4.96 (1.99 to 12.36$)$ & 0.001 & $2.84(1.25$ to 6.40$)$ & 0.01 \\
\hline Other resistance & - & - & $1.33(0.57$ to 3.10$)$ & 0.52 & $0.7(0.34$ to 1.43$)$ & 0.3 \\
\hline Cavities in chest radiograph & $3.70(1.81$ to 7.58$)$ & $<0.001$ & - & - & - & - \\
\hline $\begin{array}{l}\text { Time interval between diagnosis } \\
\text { and treatment (months) }\end{array}$ & 1.02 (1.01 to 1.04$)$ & $<0.001$ & - & - & - & - \\
\hline Treatment default & - & - & - & - & 5.21 (3.06 to 8.87$)$ & $<0.001$ \\
\hline
\end{tabular}

OR, odds ratio; $H R$, hazards ratio; MDR, multidrug resistant; $T B$, tuberculosis; -, variable not included in the final model.

*Logistic regression analysis.

†Cox proportional hazard model. 

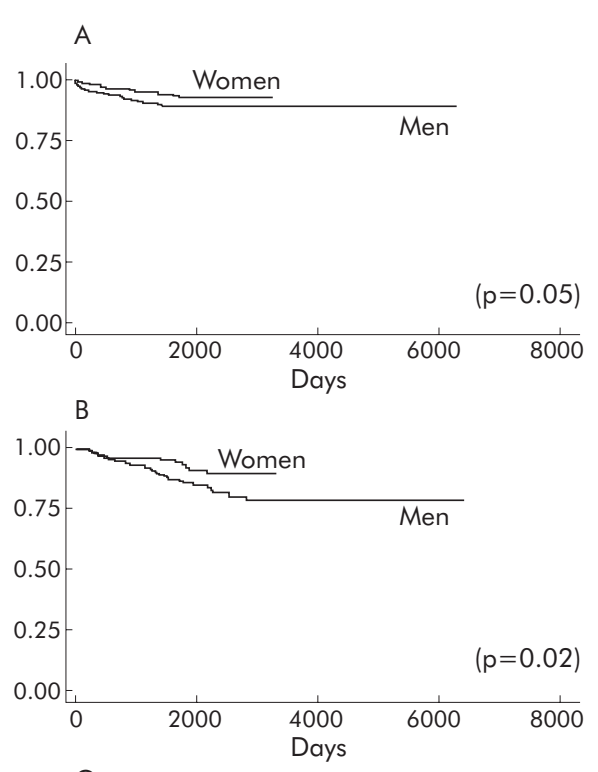

C

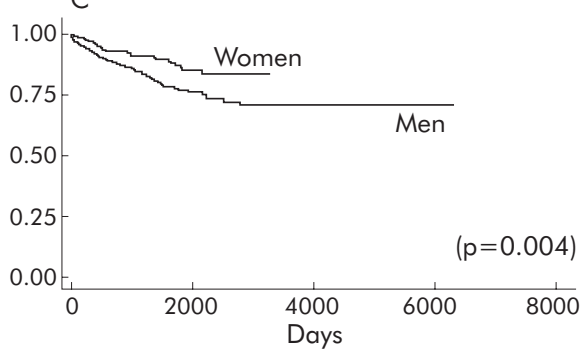

Figure 1 Kaplan-Meier survival curves by gender. (A) Death from TB $(p=0.05)$; $(B)$ death from some cause other than TB $(p=0.02)$; and $(C)$ death from all causes $(p=0.004)$.

\section{Characteristics of patients by gender}

The characteristics of the study population by gender are shown in table 2. Men were more likely than women to have had some formal education and to be from a higher socioeconomic level (as determined indirectly by household characteristics), but they were also more likely to have lived in a shelter, been imprisoned, or to report using alcohol or drugs. Men were also more likely than women to have severe clinical symptoms such as weight loss and haemoptysis at diagnosis. However, there were no significant differences between men and women in the distance from their home to the nearest healthcare service $(p=0.24)$, the median time interval between the onset of symptoms and diagnosis $(p=0.46)$, the median time interval between the onset of symptoms and treatment $(\mathrm{p}=0.18)$, and the median time interval between diagnosis and the start of treatment $(\mathrm{p}=0.22)$.

\section{Treatment outcomes by gender}

Twelve patients refused treatment. Of 568 patients for whom treatment completion could be evaluated, 427 (75.2\%) had initiated treatment within 10 days of diagnosis and 551 $(97.0 \%)$ received directly observed therapy (DOTS). The treatment outcomes overall were as follows: 471 (82.9\%) cured $(419(73.8 \%)$ of whom had bacteriological confirmation); 52 (9.2\%) defaulted; 16 (2.8\%) failed treatment; 17 $(3.0 \%)$ died during treatment; and $12(2.1 \%)$ transferred out of the study area. In the bivariate analysis, men were more likely than women to default from treatment $(p=0.004)$. Controlling for socioeconomic characteristics, radiological lesions, and the mean time interval between diagnosis and treatment in a multivariate logistic regression analysis, men were still more likely than women to default (odds ratio (OR) $3.30,95 \%$ CI 1.46 to $7.43, \mathrm{p}=0.004$ ); table 3 ). Patients were followed for a mean (SD) of 40.81 (32.43) months. The follow up time was similar for men (48.33 months) and for women (49.48 months, $\mathrm{p}=0.66)$. After completing treatment, men were more likely than women to have a subsequent episode of $\mathrm{TB}$ and to require retreatment $(\mathrm{p}=0.01$, table 2). The Cox adjusted hazards ratio (HR) for retreatment, controlling for diabetes and drug resistance, was higher among men than among women (HR 3.15, 95\% CI 1.38 to $7.22, \mathrm{p}=0.007$; table 3 ).

One hundred and eighteen patients died during the study period; death was due to TB in 52 of these $(44.1 \%)$. Of these 52 patients, three were untreated, 17 died during treatment, and 32 died after treatment. Four of the 12 patients who refused treatment, all of whom were men, died. The Cox adjusted hazards ratios for mortality from TB controlling for age, body mass index, weight loss, HIV infection, drug resistance, and treatment default was higher among men than among women (HR 2.23, 95\% CI 1.25 to 3.99, p = 0.007; table 3). Men had lower survival rates when death due to TB $(p=0.05)$, death from other causes $(p=0.02)$, and death from all causes $(p=0.004)$ were assessed (fig 1$)$.

Since alcohol use was more frequent among men, we evaluated models that included alcohol as an independent variable. Men were more likely to default, require retreatment, or die from TB when models were also adjusted by use of alcohol.

\section{DISCUSSION}

In this population based study conducted in a developing country with endemic rates of TB, we provide data indicating higher rates of bacteriologically proven pulmonary TB and more severe clinical consequences among men than women. By using molecular epidemiological techniques, we further determined that higher rates among men are the result of both reactivation of latent infection and of recent TB transmission. Public health strategies that aim to reduce TB will need to address both disease processes.

Data indicating higher TB rates for men, particularly when obtained from developing countries, ${ }^{17} 18$ have been highly controversial and have often been attributed to gender based differences in access to health care. ${ }^{19}$ Existing evidence indicates that the access to and use of healthcare services in Mexico is similar in men and women and, in fact, women use the health services more frequently than men. ${ }^{20}$ Although the women in our study came from lower socioeconomic groups than the men, these differences did not represent an obstacle for pulmonary TB screening, diagnosis, and treatment in the study area since such services are available free of charge through the public health sector in Mexico. The proportion of women who reported coughing for at least 2 weeks, provided sputum samples, and were screened for TB was greater than the proportion of men who were screened. There were no significant gender based differences in the distance to the nearest health centre and in the time interval between the onset of symptoms and the start of antituberculosis treatment. Although the median time intervals to diagnosis and treatment were similar between men and women, men had more severe clinical symptoms at the time of diagnosis. It is possible that symptoms such as coughing might initially have been attributed to other causes such as tobacco use, therefore men were symptomatic for longer before seeking care. We consider that the higher rate of pulmonary TB detected in men is not attributable to unequal access to health services for diagnosis and treatment. A recent study in south India 
also reported that women were more likely than men to access the healthcare services. ${ }^{21}$

Differences in TB rates have also been attributed to biological phenomena. It has been suggested that the propensity to develop disease after infection with $M$ tuberculosis (progression rate) may be greater in women of reproductive age than in men of the same age, whereas men have higher rates of progression when older. ${ }^{22}{ }^{23}$ Co-morbid conditions such as HIV infection, ${ }^{24}$ diabetes, ${ }^{25}$ and cirrhosis ${ }^{26}$ could also affect the rate at which TB occurs, and their prevalence could vary by gender. We also note that men not only had higher rates of pulmonary TB, but also had more severe clinical symptoms when diagnosed with TB.

The higher rates of pulmonary TB among the men in our study are partially explained by the local transmission dynamics, particularly in crowded, poorly ventilated or nosocomial settings. Men are more likely to report risk factors that have been associated with exposure to $\mathrm{TB}^{27}$ such as imprisonment ${ }^{28}$ or prior residence in a shelter. ${ }^{29}$ We previously described an outbreak of TB in the study area occurring in clandestine bars whose customers were mainly men. ${ }^{7}$ Men also reported more frequent use of alcohol and tobacco, behaviours that may influence the rate at which TB infection progresses to active disease. ${ }^{30}{ }^{31}$ Evaluation of male gender and alcohol by logistic regression analyses and Cox models showed that men with $\mathrm{TB}$ are at a higher risk of a poor treatment outcome, independent of alcohol use.

There were significant differences in the outcomes of antituberculosis treatment between men and women. Although women were just as likely as men to be treated with DOTS, men were more likely to default from treatment. The behaviour patterns of non-adherent male patients have been amply described. ${ }^{32}{ }^{33}$ As has been reported previously, ${ }^{34}$ men were more likely than women to require retreatment, probably because of defaulting from treatment. The probability of death caused by TB among men more than doubled that of women when adjusted for variables known to be associated with mortality such as drug resistance and HIV infection. ${ }^{12}$ Men also had a higher probability of death due to other causes and of death due to all causes. This higher probability of death due to TB among men has been confirmed elsewhere. ${ }^{35}$

The conclusions that can be drawn from our study are limited by several potential biases. Determining the cause of death can be a complex process. In this study we used a combination of criteria (clinical, bacteriological, caregiver interview, and/or death certificate) to ascertain the cause of death ${ }^{2}{ }^{36}$ which allowed us to estimate mortality rates. We have validated this method previously. ${ }^{12}$ The cause of death profile derived from interviewing a close caregiver or verbal autopsy has also been found to be useful by others. ${ }^{36}$ It should be noted that we studied only bacteriologically proven pulmonary TB cases. Our data may not be generalisable to patients with fewer bacilli and less severe symptomatology since our study population differed in bacilli concentrations and clinical manifestations from the total pulmonary TB cases. Finally, we only explored epidemiological and clinical information; other sociological and behavioural aspects which might determine gender differentials were not included in our study. Nevertheless, our population based study allowed us to calculate unbiased pulmonary TB rates for men and women regardless of the complexity of other factors that were not considered.

The results of our study support the need to devise and implement TB control strategies to block further TB transmission, including better case finding and confirmation that each TB patient is cured. Our data also show that increased screening and treatment of latent infection will be needed to decrease the incidence of reactivated disease.

\section{ACKNOWLEDGEMENTS}

The authors thank Dr Carmen Soler for performing the HIV tests, Drs Manuel Tielve, Ruben Acevedo and Luis Felipe Alva for interpreting the chest radiographs, and the personnel of the Orizaba Health Jurisdiction who supported the study.

\section{Authors' affiliations}

M-E Jiménez-Corona, L García-García, L Ferreyra-Reyes, B CanoArellano, S Canizales-Quintero, Instituto Nacional de Salud Pública (INSP), Cuernavaca Morelos, México

K DeRiemer, Stanford University, Palo Alto, California, USA

M Bobadilla-del-Valle, A Martínez-Gamboa, J Sifuentes-Osornio, A Ponce-de-León, Instituto Nacional de Ciencias Médicas y de Nutrición "Salvador Zubirán" (INCMNSZ) México, DF, México

P M Small, Bill and Melinda Gates Foundation, Seattle, Washington, USA

This study was supported by the Mexican Secretariat of Health, the National Institutes of Health of the United States (Al35969 and FIC K01TW000001), the Wellcome Trust (176W009), the Howard Hughes Medical Institute (55000632), and the Mexican Council of Science and Technology (G26264M and 30987-M). The funding agencies did not participate in the study design or in the decision to submit the paper for publication.

Competing interests: none.

\section{REFERENCES}

1 Connolly M, Nunn P. Women and tuberculosis. World Health Stat $Q$ 1996;49:115-9.

2 World Health Organization. Global tuberculosis control. Surveillance planning, financing. Geneva: World Health Organization, 2004. Available from http://www.who.int/gtb.

3 Martinez AN, Rhee JT, Small PM, et al. Gender differences in the epidemiology of tuberculosis in San Francisco. Int J Tuberc Lung Dis 2000:4:26-31

4 Borgdorff MW, Nagaldkerke NJ, Dye C, et al. Gender and tuberculosis: a comparison of prevalence surveys with notification data to explore gender differences in case detection. Int J Tuberc Lung Dis 2000:4:123-32.

5 Uplekar M, Rangan S, Ogden J. Gender and tuberculosis control: towards a strategy for research and action, WHO/TB/2000.280. Geneva: World Health Organization, 1999

6 Instituto Nacional de Estadística, Geografía e Informática (INEGI). XII Censo General de Población y Vivienda, 2000. Mexico, 2000. Available from http://www.inegi.gob.mx/est/default.asp?c = 703 (accessed 30 November 2005).

7 García-García M, Palacios-Martinez M, Ponce de León A, et al. The role of core groups in transmitting Mycobacterium tuberculosis in a high prevalence community in Southern Mexico. Int J Tuberc Lung Dis 2000;4:12-7.

8 Instituto Nacional de Estadística, Geografía e Informática (INEGI). XII Censo General de Población y Vivienda 2000. Resultados preliminares. Aguascalientes; Ags. Estados Unidos Mexicanos. Instituto Nacional de Estadística, Geografía e Informática, 2000:10.

9 Secretaria de Salud. Dirección general de epidemiología. Sistema Unico de Información, México, $2001 ; 18: 4-7$.

10 Secretaría de Salud. Para la prevención y control de la tuberculosis en la atención primaria a la salud. Modificación a la Norma Oficial Mexicana. NOM-006-SSA2-1993. Diario Oficial de la Federación, 2000.

11 Garcia-Garcia ML, Ponce de Leon A, Jimenez-Corona ME, et al. Clinical consequences and transmissibility of drug resistant tuberculosis in southern México. Arch Intern Med 2000; 160:630-6.

12 Garcia-Garcia ML, Ponce-de-Leon A, Garcia-Sancho MC, et al. Tuberculosisrelated deaths within a well-functioning DOTS control program. Emerg Infect Dis 2002;8:1327-33.

13 Metchock BG, Nolte FS, Wallace RJ Jr. Mycobacterium. In: Murray PR, Baron EJ, Pfaller MA, et al. Manual of clinical microbiology. 7th ed. Washington: ASM Press, 1999:399-437.

14 DeRiemer K, Garcia-Garcia ML, Ponce de Leon-Garduno A, et al. Classification of drug-resistant tuberculosis. Lancet 2000;356:1931-2.

15 Instituto Nacional de Estadística, Geografía, e Informática (INEGI). XII Censo General de Población y Vivienda 2000. Estados Unidos Mexicanos, México, 2000. Available from http://www.inegi.gob.mx.

16 Mantel N. Evaluation of survival data and two new rank-order statistics arising from its consideration. Cancer Chemother Rep 1966:50:163-70.

17 Begum V, de Colombani P, Das Gupta S, et al. Tuberculosis and patient gender in Bangladesh: gender differences in diagnosis and treatment outcome. Int J Tuberc Lung Dis 2001;5:604-10.

18 Long NH, Diwan VK, Winkvist A. Difference in symptoms suggesting pulmonary tuberculosis among men and women. J Clin Epidemiol 2002;55: 115-20.

19 Uplekar MW, Rangan S, Weiss MG, et al. Attention to gender issues in tuberculosis control. Int J Tuberc Lung Dis 2001;5:220-4. 
20 Secretaría de Salud, Subsecretaría de Prevención y Control de Enfermedades, Instituto Nacional de Salud Pública. Encuesta Nacional de Salud 2000, 1st ed. 2000:41-50.

21 Balasubramanian R, Garg R, Santha T, et al. Gender disparities in tuberculosis: report from a rural DOTS programme in south India. Int J Tuberc Lung Dis 2004;8:323-32.

22 Fine PEM. Immunities in and to tuberculosis: implications for pathogenesis and vaccination. In: Porter JDH, McAdam KPWJ, eds. Tuberculosis back to the future. Chichester: Wiley and Sons, 1993:53-78

23 Murray CJL. Social, economic and operational research on tuberculosis: recent studies and some priority questions. Bull Int Union Tuberc Lung Dis $1991 ; 66: 149-56$.

24 Bates I, Fenton C, Gruber J, et al. Vulnerability to malaria, tuberculosis, and HIV/AID infection and disease. Part 1: Determinants operating at individual and household level. Lancet Infect Dis 2004:4:267-77.

25 Ponce-de-Leon A, Garcia-Garcia ML, Garcia-Sancho MC, et al. Tuberculosis and diabetes in southern Mexico. Diabetes Care 2004:27:1584-90.

26 Thulstrup AM, Molle I, Svendsen N, et al. Incidence and prognosis of tuberculosis in patients with cirrhosis of the liver. A Danish nationwide population based study. Epidemiol Infect $2000 ; 124: 221-5$

27 Caracta CF. Gender differences in pulmonary disease. Mt Sinai J Med 2003;70:215-24.
28 Tekkel M, Rahu M, Loit HM, et al. Risk factors for pulmonary tuberculosis in Estonia. Int J Tuberc Lung Dis 2002;6:887-94.

29 Curtis AB, Ridzon R, Novick LF, et al. Analysis of Mycobacterium tuberculosis transmission patterns in a homeless shelter outbreak. Int J Tuberc Lung Dis 2000:4:308-13.

30 Godoy P, Nogues A, Alseda M, et al. Risk factors associated to tuberculosis patients with positive sputum microscopy. Gac Sanit 2001;15:506-12.

31 Kolappan C, Gopi PG. Tobacco smoking and pulmonary tuberculosis. Thorax 2002; $57: 964-6$

32 Chan-Yeung M, Noertiojo K, Leung CC, et al. Prevalence and predictors of default from tuberculosis treatment in Hong Kong. Hong Kong Med J 2003:9:263-8

33 Samman $Y$, Krayem A, Haidar M, et al. Treatment outcome of tuberculosis among Saudi nationals: role of drug resistance and compliance. Clin Microbiol Infect 2003;9:289-94.

34 Oliveira HB, Moreira Filho DC. Treatment abandonment and tuberculosis recurrence: aspects of previous episodes, Brazil, 1993-1994. Rev Saude Publica 2000:34:437-41.

35 Borgdorff MW, Veen J, Kalisvaart NA, et al. Mortality among tuberculosis patients in The Netherlands in the period 1993-1995. Eur Respir J 1998;11:816-20.

36 Kahn K, Tollman SM, Garenne M, et al. Who dies from what? Determining cause of death in South Africa's rural north-east. Trop Med Int Health 1999;4:433-14.

\section{LUNG ALERT}

Inhaled hypertonic saline reduces pulmonary exacerbations in cystic fibrosis

$\Delta$ Elkins MR, Robinson M, Rose BR, et al. A controlled trial of long-term inhaled hypertonic saline in patients with cystic fibrosis. N Engl J Med 2006;354:229-40

$\mathrm{S}$

hort term administration of hypertonic saline has been shown to improve lung function in cystic fibrosis. The authors conducted a double blind, parallel group trial over a 48 week period with 164 patients aged at least 6 years randomly assigned to either 7\% (hypertonic) or $0.9 \%$ saline (control). A bronchodilator was administered before each inhalation of the study solution.

There was no significant difference between the two groups in the primary outcome measure-the rate of change in lung function. However, in the hypertonic saline group the absolute level of lung function, averaged over the period from 4 to 48 weeks after randomisation, was moderately higher than in the control group $(p=0.03): F_{1} V_{1} 3.2 \%(95 \%$ CI 0.1 to 6.2 ) higher; FVC $2.8 \%$ (95\% CI 0.4 to 5.2 ) higher.

There were fewer pulmonary exacerbations (defined by signs and symptoms) in the hypertonic saline group than in the control group, with 2.74 exacerbations per participant in the control group and 1.32 in the hypertonic saline group (difference 1.42 , 95\% CI 0.86 to $1.99, \mathrm{p}<0.001)$. Furthermore, $41 \%$ of the hypertonic saline group were exacerbation-free over 48 weeks compared with $16 \%$ of the control group $(\mathrm{p}<0.001)$. However, these differences were largely confined to the first 3 months of treatment and were paralleled by a decrease in compliance in patients over time.

This study suggests that hypertonic saline (preceded by a bronchodilator) may have potential as a long term intervention for cystic fibrosis.

A J Mackay Senior House Officer, Royal Free Hospital, London, UK; malexmackay@hotmail.com 